\title{
Astrophysics in the 1890s - The Dawn of a New Age in Astronomy
}

\section{J. B. Hearnshaw}

\author{
Department of Physics and Astronomy, University of Canterbury, \\ Christchurch, New Zealand
}

\begin{abstract}
The Konkoly Observatory was established as a public institution in Hungary in 1899, when Nicholas von Konkoly Thege (18421916) bequethed his private observatory at Ógyalla to the state. Konkoly himself was one of the pioneers in the new science of astrophysics, and he was an expert in astronomical instruments used for photometry and spectroscopy.

In this paper I review, from a global perspective, the 1890s decade as ten years of prodigious achievements in stellar astronomy, with many huge programmes being launched and undertaken in spectral classification, radial velocities, photometry and astrometry. New astrophysical observatories were founded in America and Europe and new large telescopes designed and built, and the first international conferences were held in astronomy.

Astrophysics was still a largely qualitative science in the $1890 \mathrm{~s}$, but this was soon to change in the early years of the present century. I review the development of astrophysics in the 1890s, its interaction with new discoveries in physics, and comment on some of the large projects in stellar photometry, spectroscopy and astrometry and especially the influence of photography on observational astrophysics. The place of Nicholas von Konkoly in this overall endeavour is discussed and I pay tribute to his considerable influence and to the observatory he founded. A century of state-funded astronomy in Hungary has been the result.
\end{abstract}

\section{Introduction}

This meeting has been timed with great care, not only to coincide with a total solar eclipse, but also to mark the centenary of the founding of the Konkoly Observatory as a state institution, and therefore as Hungary's national observatory. My review is to celebrate this centenary.

We live in an age of unprecedented progress in science, including astronomy. The 1990s will be remembered as an era dominated by the CCD detector, by the Hubble Space Telescope and by the new class of $8-10-\mathrm{m}$ ground-based telescopes, which have and will bring new knowledge in astronomy, especially on distant galaxies, quasars and the early universe.

But one hundred years ago, the 1890s decade was also an era of unparalleled progress and optimism. The progress was in stellar astronomy and the 
early application of astrophysics to the stars. The $1890 \mathrm{~s}$ was one of the most dynamic and successful decades in astronomy's history over the last two and a half centuries.

Here I review the progress of stellar astronomy and astrophysics in the $1890 \mathrm{~s}$ decade in order to mark the founding of the Konkoly Observatory in 1899 as a state institution, and in order to pay homage to the work of the great Hungarian astronomer, Nicholas von Konkoly, then at the height of his powers.

\section{Visual Photometry}

The practice of visual photometry was still widespread 100 years ago. This was an age of large programmes to collect fundamental stellar data on a massive scale. The Córdoba Durchmusterung, the Harvard Photometry, Pritchard's Uranometria Nova Oxoniensis and the Potsdamer Durchmusterung were all products of the late nineteenth century, using (in the case of Córdoba) eye estimation of magnitudes, or measurements of star brightness by various types of visual photometer, but with only modest precision.

\section{Photographic Photometry}

\subsection{Focal Images}

In spite of the large programmes in visual photometry, photography came to dominate completely all aspects of astronomy in the $1890 \mathrm{~s}$, just as the CCD is doing so today. Photographic photometry heralded unheard-of new opportunities, but also brought many at first unforeseen problems. Astronomers, especially those at Harvard, at the Cape and in Paris, embraced this new technology of the dry emulsion. And so were launched the Cape Photographic Durchmusterung (CPD) by Gill and Kapteyn and the Carte du Ciel (CdC) by Mouchez, the Henry brothers and others.

The CPD was especially significant, as it represented the first major project of international cooperation in astronomy, between two institutions, the Cape Observatory and the Groningen Astronomical Laboratory, as equal partners, one involved with observation, the other with the reduction of the plates.

This was followed soon after with the ill-fated Carte du Ciel project, involving international collaboration on a much larger scale, with 18 participating observatories. The plan was to record the whole sky photographically to magnitude 14 on 44108 plates, as well as to measure magnitudes and positions for some two million stars to magnitude 11 (the Astrographic Catalogue). This ambitious programme was estimated to take $17-25$ years and cost 6.25 million French francs. After 75 years it was abandoned and never fully completed in a uniform manner.

There are several reasons why the Carte $d u$ Ciel project was never fully completed - but the main one was that in the 1890 s, there was a poor understanding of the properties of photographic plates themselves, and no generally agreed and reliable method of obtaining stellar magnitudes from the photographic images. At first it was thought that application of the reciprocity law, which implied that an exposure 2.5 times as long would gain just one magnitude, would pro- 
vide a convenient and simple way of calibrating plates, using multiple exposures on the same plate. By 1900 it was realised that the reciprocity law was not valid. More complicated procedures would be necessary for plate calibration and for transferring standard magnitude sequences from one region of the sky to another. These problems were never satisfactorily resolved in the first three decades of the Carte du Ciel project.

But one highly significant development came from the $\mathrm{CdC}$ project. A series of International Astrographic Congresses was held, the first being in Paris in April 1887. It brought together 56 astronomers from 18 countries. This was the first international conference in astronomy and one of the earliest in any science.

\subsection{Extrafocal Images}

Some astronomers recognised the impracticality of observing accurate magnitudes from focal images and that better precision could be attained by defocussing the telescope and uniformly spreading the light over a small area of plate. One of the first careful investigators in the science of quantitative photographic photometry, measuring plate densities, was Karl Schwarzschild, who devised his so-called Schraffierkassette (or jiggle camera) for measuring magnitudes of bright stars, in his Göttinger Aktinometrie.

\section{Variable Stars}

One immediate result from the practice of celestial photography was the large increase in the number of known variable stars. In 1890 , only 260 were catalogued, nearly all from visual observations. The number had increased about fourfold by the end of the century and stood at 3748 in 1907. This large increase came about from celestial photography, largely at Harvard, with Solon Bailey, Williamina Fleming and Henrietta. Leavitt being the principal discoverers. About half the new variables found during the 1890 s were in the Magellanic Clouds - this was the beginning of serious interest in the stellar content of our satellite galaxies.

Some notable variable stars were observed for the first time in the $1890 \mathrm{~s}$ decade. These included $\mathrm{Z}$ Centauri (the first supernova whose spectrum was recorded photographically), the naked-eye nova, Nova Aurigae 1891 and the spectra of $\mathrm{P}$ Cygni and $\eta$ Carinae.

\section{Photoelectric Photometry}

Photographic photometry was a major industry in the $1890 \mathrm{~s}$; less well known were the first experiments in photoelectric photometry by George Minchin and William Monck in Ireland, using a selenium photovoltaic cell. The first successful detection of starlight by this means was in 1892 .

William Monck was a Dublin philosophy professor and amateur astronomer who first recognised the dichotomy in luminosity for late-type stars in 1892, a discovery based on proper motions, that predated the work of Hertzsprung by over a decade. 


\section{Stellar Spectra and Spectral Classification}

The 1890s was noted for its advances in stellar spectral classification, perhaps more so than any other endeavour in sidereal astronomy. The Harvard astronomers, Pickering, Cannon, Fleming, and Maury, were pre-eminent in this field, but Vogel and the Potsdam observers and also Norman Lockyer and Nicholas von Konkoly were also active at about this time. Terrestrial helium was discovered in 1896, and this had a notable influence on subsequent stellar spectral classification. He II lines in $\zeta$ Puppis were discovered by Pickering in 1897, but were at first thought to be due to hydrogen under unusual conditions, as the lines corresponded to the Balmer series, but with an additional line between each pair of adjacent Balmer lines.

The work of the Henry Draper Catalogue was soon to begin, but the forerunner, the Draper Memorial Catalogue of Stellar Spectra came out in 1890, and Antonia Maury's own scheme of classification was published in 1897, in which she recognised the narrow-lined c-type stars, which we now know (thanks to Hertzsprung) to be supergiants.

\section{Radial Velocities}

The first reliable stellar radial velocities also date from this remarkable decade of astronomical achievement, as a result of the photographic spectra obtained by Hermann Carl Vogel and Julius Scheiner at Potsdam, from 1888 to 1892. The precision was about $2.5 \mathrm{~km} \mathrm{~s}^{-1}$ and the techniques developed were copied and refined by many others over the next 100 years, especially by W. W. Campbell at Lick. The first spectroscopic binary discoveries also date from this time (in fact 1889) from the work at Harvard and Potsdam. As many as 306 had been discovered by 1910 .

Photographic radial-velocity measurements became a popular activity at many observatories; the Lick observers expanded this work to the southern hemisphere early in the new century, while Frost at Yerkes and Belopolsky at Pulkovo also became active observers. We should remember, however, that James Keeler, using a grating spectroscope on the great Lick refractor, was the only observer to measure reliable Doppler shifts visually, which he did for bright stars and gaseous nebulae in $1890-91$.

\section{Galaxies}

This was an age of new astrophysical discovery, especially in the realm of stellar astronomy. Galaxies as external island universes were still a matter for speculation, but one crucial observation by Scheiner in 1899, which, after $7 \frac{1}{2}$ hours' exposure, showed a star-like absorption line spectrum for the Andromeda spiral, M31, was a vital clue to its stellar nature. This observation was discussed by Shapley and Curtis in the Great Debate of 1920. 


\section{New Observatories}

The 1890s was a decade when astrophysics, especially as a result of spectroscopy and photography, was applied for the first time to stars. The methods were still largely descriptive and qualitative, but the results were the basis for later quantitative analysis, especially from the $1920 \mathrm{~s}$. New results in physics were combined in the interpretation of astronomical spectra, most notably in Saha's ionisation theory, but also in Bohr's atomic theory, arising from the discovery of the electron and of the nuclear atom.

As a result, new observatories were established in the late nineteenth or early twentieth centuries, several being explicitly for the study of astrophysics. Notable were those at Potsdam (1873), Lick (1887), Harvard's Boyden Station (1890), the Vatican (1891), Edinburgh (1896), Meudon (1897), HeidelbergKönigstuhl (1898), Konkoly (Ógyalla, later Budapest) (1899) and Mt Wilson (1904).

They were equipped with new large telescopes, notably the giant refractors of Lick, Yerkes, and Potsdam, as well as the 1-m reflector at Meudon, and another of similar size at the Lick southern station in Chile, and prism spectrographs became the standard items of equipment for astrophysical research at these institutions.

\section{Miklós Konkoly Thege}

And now we come to Nicholas (in Hungarian Miklós) von Konkoly Thege (18421916), who was at the height of his powers in the 1890s. Konkoly was a Hungarian nobleman, of independent means, who developed a passionate interest for astronomy, and in particular for astrophysics. He studied in Budapest and Berlin, and founded his private observatory in Ógyalla in 1871. This he equipped with some of the best instruments of the day, including some that he designed and built himself. He was among the first observers of the spectrum of $\mathrm{S}$ Andromedae, the naked-eye supernova of 1885 . He corresponded widely with European astronomers, and travelled to meet with many of them, including his famous English counterpart, William Huggins. He also encouraged and collaborated with other Hungarian astronomers, in particular Eugen von Gothard, and Radó Kövesligethy; with the latter he published a catalogue of spectral classifications for 2022 stars on the Vogel system in 1887.

Konkoly wrote three textbooks on observational astronomy (Konkoly 1883, $1887,1890)$, and his love of instruments comes through in these works, all written in German. But his main legacy came when he bequethed his private Ógyalla Observatory to the Hungarian state in 1899 , thereby creating the first statefunded observatory in Hungary, which he directed until 1916, the year of his death.

You will note that Konkoly timed his bequest with great care, so as to be just 100 years before a significant total solar eclipse of the Sun in Europe. This meeting, to celebrate the Konkoly Observatory centenary, to observe the eclipse, and, if time permits, to discuss pulsating variable stars, is the outcome of Konkoly's munificence. 


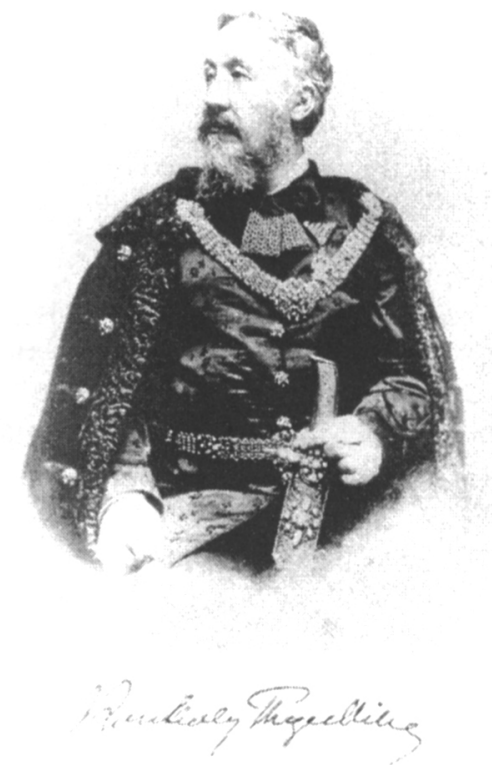

Figure 1. Nicholas von Konkoly Thege

After the Great War, the Ógyalla Observatory was no longer in Hungary, so the institution was relocated in Budapest on Svabhegy in 1922, where it became known as the Konkoly Observatory. A proud tradition of 100 years of state-funded astronomy in Hungary has been the result.

Further detailed information on the historical development of astrophysics can be found in this author's two books (Hearnshaw 1986, 1996).

\section{References}

Hearnshaw, J. B. 1986, The Analysis of Starlight, Cambridge Univ. Press, Cambridge, pp. xv +531

Hearnshaw, J. B. 1996, The Measurement of Starlight, Cambridge Univ. Press, Cambridge, pp. xiv +511

Konkoly, N. von 1883, Praktische Anleitung zur Anstellung astronomischer Beobachtungen mit besonderer Rücksicht auf die Astrophysik, nebst einer modernen Instrumentenkunde. Braunschweig.

Konkoly, N. von 1887, Praktische Anleitung zur Himmelsphotographie nebst einer kurzgefaßten Anleitung zur modernen photographischen Operation und die Spectralphotographie im Cabinet. Halle.

Konkoly, N. von 1890, Handbuch für Spectroscopiker im Cabinet und am Fernrohr. Practische Winke für Anfänger auf dem Gebiete der Spectralanalyse. Halle a.S. 